\title{
PREPARATION OF CONSTRUCTION PRODUCTION OF METAL SHEET FOR MEANS OF TRANSPORT
}

\author{
Piotr Penkała', Beata Płowaś \\ 1 Institute of Technological Systems of Information, Faculty of Mechanical Engineering, Nadbystrzycka 36, \\ 20-781 Lublin, Poland, e-mail: p.penkala@pollub.pl \\ 2 Institute of Technical Sciences and Aviation, The State School of Higher Education in Chełm, Pocztowa 54, \\ 22-100 Chełm, Poland,, e-mal: bplowas@pwsz.chelm.pl
}

Received: 2012.13.28

Accepted: 2013.01.22

Published: 2013.03.15

\begin{abstract}
The design of sheet metal parts, pressed, used in the automotive industry is very complicated. Many factors influence the final shape of the part. Contemporary designer does not need to have the knowledge needed to understand the essence of its all requirements that are placed on parts of the body. It is only important that they are aware of their existence and know who in the company can help them in their fulfilment of the construction. Nowadays, only the constructor creates a CAD model geometry, which is assumed to provide the functionality. The rest of the aspects such as the provision of adequate stiffness, manufacturability, assembly features, vibration analysis, etc., are the arena of other specialists. This is the essence of constructing simultaneous, where many cell companies often work on the same element, giving it a set of features impossible to obtain by one expert on everything. Therefore, the role of the designer is often limited to being only a CAD system operator.
\end{abstract}

Keywords: simultaneous construction, pressed parts, CAD, curvilinear surfaces.

\section{INTRODUCTION}

Constant increase of consumers' requirements entail an increase of competition between car producers, what generates increasingly high expectations towards product development, not only to pressed parts, but also the whole vehicle [1]. The development is aimed at modernity, functionality, effectiveness, productivity, quality and uniqueness. Considering these aspects from the point of view of highest profitability (what is presently most important), one can additionally state that good style and image of the product are more important than all other features and are the most important factors which decides about clients' choice [1].

In case of constructing the elements of car body, four most important objectives are planned to be fulfilled: functionality, minimum weight, high passive safety and low costs of the enter- prise [2]. Additionally, one should consider not only about the features of an individual sheet metal part, but also about its interactions with neighbouring parts. Simultaneous design should be conducted in such a way to make all the neighbouring parts play their roles to be assembled and have positive look at lowest possible cost [3]. Therefore, during the development at least such aspects as ensuring the possibility to connect one sheet metal element with another, i.e. ensuring appropriate amount of space for welding tongs (at least $5 \mathrm{~mm}$ between the tongs and another element of the car body). Additionally, in case of pressure welding the width of connecting area must be at least $12 \mathrm{~mm}$ [4]. Constructor must take consider such aspects as tolerance, special properties of the materials the elements are made of, number of operations necessary to make the element, price of material, ensuring low mass, high resistance to humidity and corrosion. In case of the elements 
of platen wall and the floor it is important that the sheet metal element have enough places with minimum curvature of $150 \mathrm{~mm}$ and the diameter of $30 \mathrm{~mm}$ for welding the bolts for fixing devices, hydraulic wires and fuel pipes. One should also consider occasional loads resulting from e.g. lifting the car with a hydraulic ramp.

Fulfilling all these requirements frequently lead to conflicts between the experts from different fields. Therefore, in case of so complicated processes, simultaneous development is necessary so that the construction is made by all stakeholders within the institution at the same time. In the simulation process the exchange of information and cooperation at the level of individual employees and departments is crucial. Good example of simultaneous development is a situation when one of bolts is impossible to weld because there is a collision between the welding head and another part of the body. In order to solve this problem, a meeting of all specialists responsible for the issue from a given field is organised and they search for the cheapest solution to the problem. In this case there is a number of possibilities. Additional welding dock can be added in the assembly line, which fixes the bolt before the colliding element. Unfortunately, this generates additional coast in the station and increases the production time. The bolt can be moved to a different place, however, then it is required to move. In the new place there need to be enough space for it and the generated heat cannot have negative impact on other devices. Additionally, the assembly of the whole system must be analyzed (electronic device plus a handle) in a new position.
Each of the specialists responsible for individual areas must evaluate how expensive and complicated the change be. Then the costs of modifications are estimated and the cheapest and easiest option is selected. The situation shows how complicated the process of the development of pressed parts is and how the simultaneous construction works. In a traditional process, in case of head collision with the car body, new head, with the size that allows collision-less bolt fixing, should be designed,.

The advantages of this type of designing include: regular exchange of data, the necessity to accept changes by everyone, high level of flexibility in changes, better results, higher efficiency of employees, lower costs of development. The scheme of simultaneous process of development is presented in Figure 1.

\section{THE USE OF CATIA SYSTEM IN DESIGNING CAR BODY}

The construction of the outer surface, called the "strack" starts from the import of sketches in four projections to module "Sketch Tracer" in Catia. Then, in the spline function the sketches are outlined and making a digital interpretation of curves creating the main conditions of the car body (Fig. 2). Considering the fact that in case of outer construction of the car body only one part (left of right) the curves for only one side are developed. All curves are made on planes XY, $\mathrm{ZX}, \mathrm{Zy}$ or the parallel planes. Plane $\mathrm{XY}$ is parallel to the road surface, plane $\mathrm{ZX}$ is the plane of

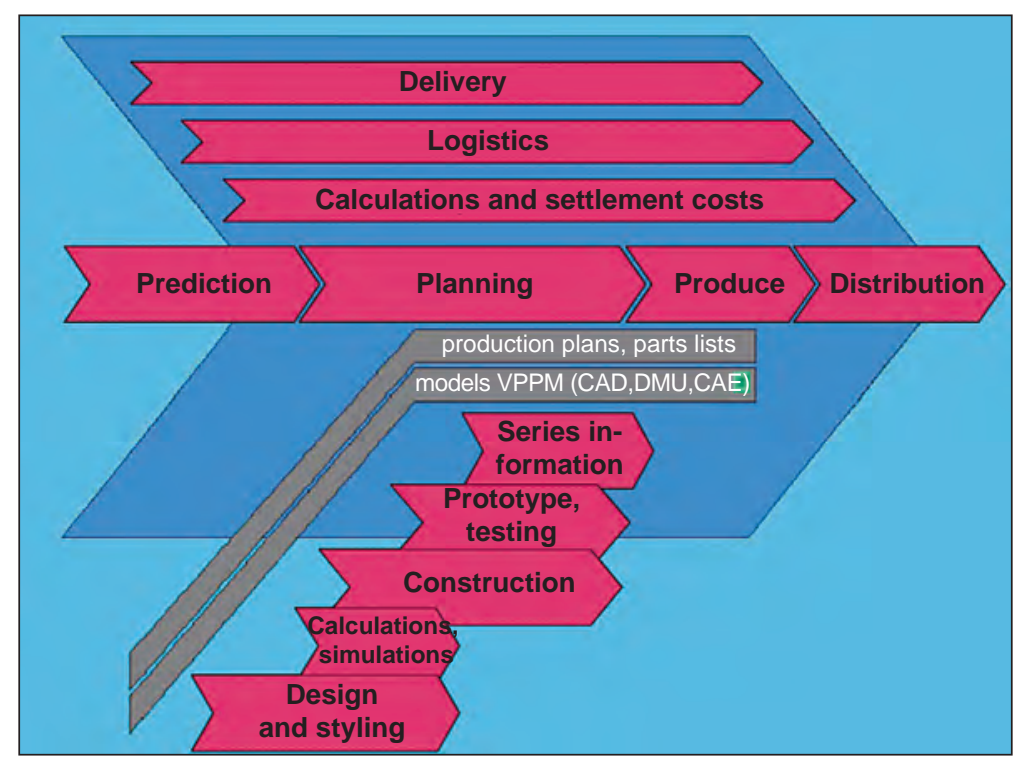

Fig. 1. Simultaneous development process [5] 


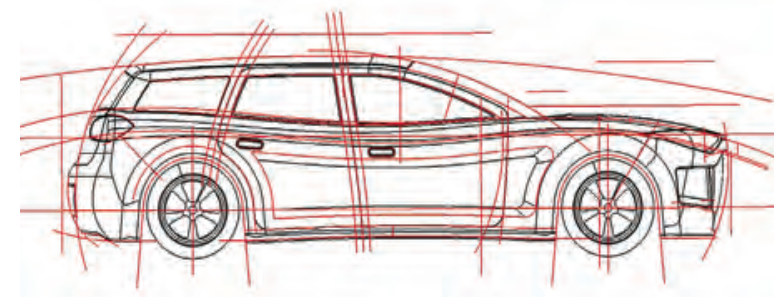

Fig. 2. Beizer curves in side projection

longitudinal symmetry, which is at the same time parallel to the direction of movement. Plane $\mathrm{ZY}$ is perpendicular to the $\mathrm{ZX}$ plane and turns into the front axis of the vehicle. The point of crossing all the planes lies exactly at the frontal axis of the car and makes a zero point for all the curves.

Considering the fact that one side of the car body is designed, all curves which lie on the YZ plane perpendicular to ZX plane, so that there was not a discontinuation of surface on the reflection according to this plane. This rule is reflected in Figure 3, where the bonding curve is tangent at the point on ZX surface to the auxiliary straight to this perpendicular straight.

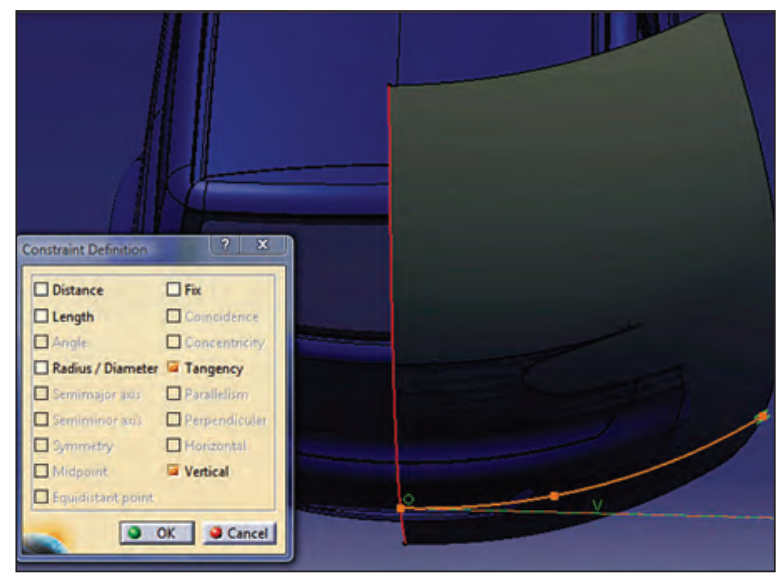

Fig. 3. Perpendicularity of bonding curve to ZX plane

The obtained curves are used to build elementary surfaces, which make the outer surface of the car body. During this operation it is important that the whole outer surface was broken into elementary surfaces this can be described with crossing curves. The rule is illustrated in Figure 4.

Each elementary fragment should be curvilinear. It is a basic rule of constructing such type of construction. straight-linear look concave, therefore, only invisible B and C class elements are used. In order to ensure curvi-linearity a tool called "Sweep" in Catia should be used. In order to use this tool, two curves, lead curve and profile are necessary. In the dialog window (Fig. 5),

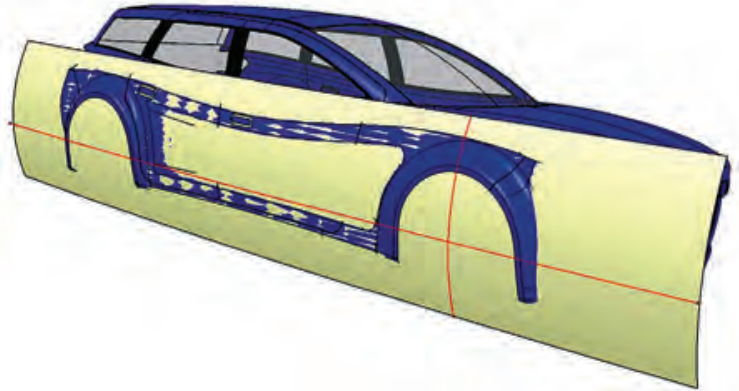

Fig. 4. Elementary side surface of the car body, described with two bonding curves

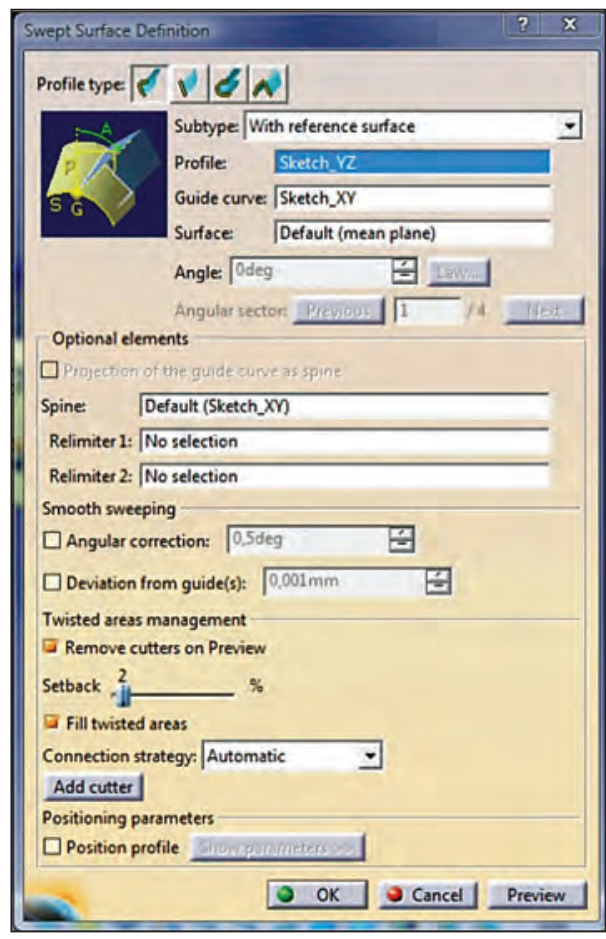

Fig. 5. Dialog window of „sweep” tool

in "Profile" and "Guide curve" bookmarks the curves must be selected.

External surface of the car body consists of a number of pieces, therefore, it is necessary to order a historic tree of the model and to place the surface and geometry necessary to build in a separate geometric "set", which should have such a name that enables the constructor to find appropriate surface in case of changes (Fig. 6). The names that correspond to the function of the surface should be used, e.g. side surface, roof, boot lid, etc. Individual pieces (Fig. 7) are connected with such functions as "fillet" and "trim". The effect of such connection should be inserted under two "sets" where the connected surfaces are present, and its name should contain the information about the pieces it connects (Fig. 8). 


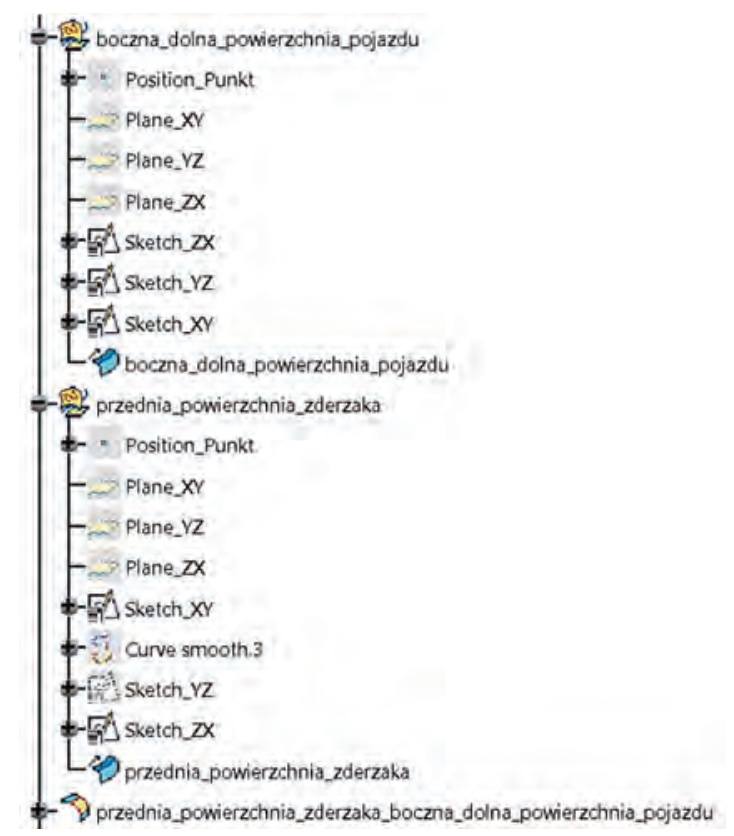

Fig. 6. Ordering the history of the model

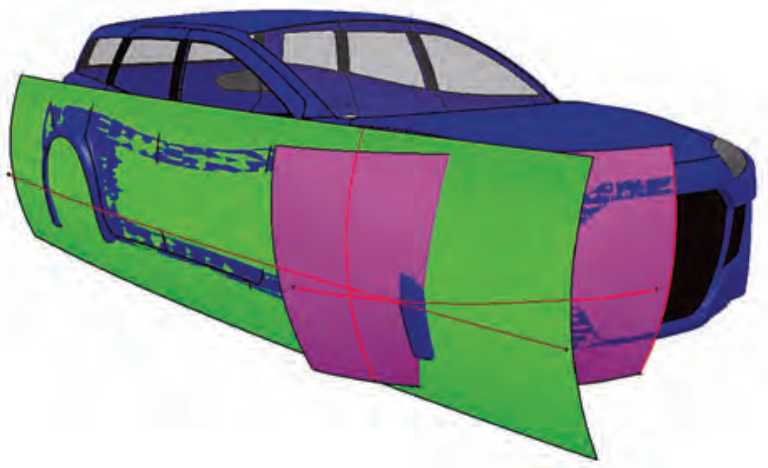

Fig. 7. Connecting the surface pieces

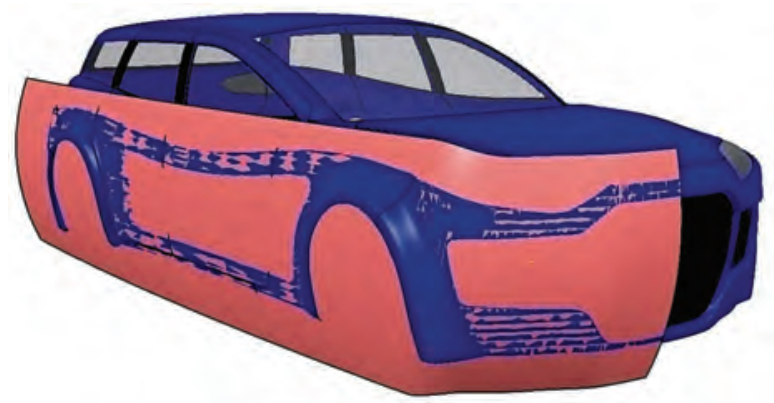

Fig. 8. The effect of connection

Each geometric set should be appropriately constructed so that possible changes in geometry were easy to do. Each car concern has its methodology to construct a history tree in Catia. The methodology defines the look of each geometric "set", but also defines the location of surfaces imported from neighbouring elements, cutting operations, drilling, cuts and solid operations. The methodology frequently exerts certain methods of constructing by providing the constructor with the so called "Model start", which is a base file that all the operations should start with. The file contains an empty history of the mode, which is filled with constructor's own operations, located in the slots determined by the start model. With such an approach, each model has the same form, regardless of the constructor that operated on it. This allows quick navigation in model history and modification of geometries by different users.

\section{DIVISION OF THE OUTER SURFACE INTO COMPONENTS}

The division of the outer surface is determined bz numerous, frequently contradictory factors. In the discussed example the division was made on the basis of design and technological assumptions for individual parts. Then, each element was checked for its manufacturability, i.e. if the depth of pressing are not too deep and if the shapes angles of formation are not too small [6].

Considering the fact that the present article is of only theoretical character, the width of spaces was $4 \mathrm{~mm}$. In industrial practices a conflict of interests appears at this point. According to car designers this interval should not be present at all; however, from technical point of view it is not possible. Thus, designers press other members of the team for the smallest possible value. On the other hand, constructors cannot allow for such an approach due to the assembly tolerances in the car bodies, which make $+/-2 \mathrm{~mm}$. This means that the used $4 \mathrm{~mm}$ space would disappear completely in case of overlapping the maximum tolerances of two neighbouring elements.

The largest possible value of the space between car body panels is in the interest of the specialists on assembly. Welding machines that position the elements against one another have also their tolerances, moreover the pressed element is also characterised by a tolerance of $+/-0.5 \mathrm{~mm}$. Therefore, considering the increasing pressure for aesthetic look, there is also a pressure for the development of pressing technologies and the assembly of pressed elements in order to limit the tolerance spaces, therefore using smaller weldings between car body panels.

In case of numerous body versions, it important that the construction was divided in such a manner that the versions have the highest possible number of mutual elements [1]. In case of closed body, the whole car body up to B column 
is identical for each version. As for the floor, it is also identical (most often) up to $\mathrm{C}$ column.

In modern constructions, where virtual crash tests are possible, the distribution of deformations in standard NCAP test at the speed of $50 \mathrm{~km} / \mathrm{h}$ is taken into consideration at the design stage. If a compromise between the designer and constructor is possible, it is done in such a way that limits the number of elements that are destroyed in the collision [1]. The course of car body division is important from the point of view of the designer, e.g. it gives the car silhouette the dynamism or elegance, and despite numerous factors in favour of its change it is not done, because the emotions the look generates are more important as they decide whether the model will be warmly welcomed in the market or not. This frequently entails the use of expensive technologies and significant increase of construction development costs, however, the expenses generate large returns if the model sales well.

Ergonomics is also an important factor that influences the car body division line. The programme that simulates human interaction with the vehicle is called Ramsis. It is used to test if the position of sitting is comfortable. The results of the simulation influence changes in door shape. Certain rule can be noticed. B column in four-door cars is often curved backwards, as in the discussed construction. Whereas, it is curved forward or upright in coupe-type of cars. This results from the posture of a person who enters the car [7].

\section{ASSEMBLY FEATURES OF A PART: WING}

Assembly analysis is a broad topic, and in case of the discussed model it was made primarily on the basis of the deformation angle in the depth of pressing. The analysis is presented on the example of a wing. For this purpose "Draft analysis" tool was used.

In order to determine initial direction of forming, edge visualisation should be switched on, and then view the model in such a way, so that all the edges are visible. Next, ,plane definition” tool must be applied (Fig. 9) and „equation” option and "Parallel to screen" must be selected. In this way a plane parallel to the screen and perpendicular to the formation direction is obtained. The final step is to make a perpendicular line, with "Line" tool, which defines the direction of the die set.

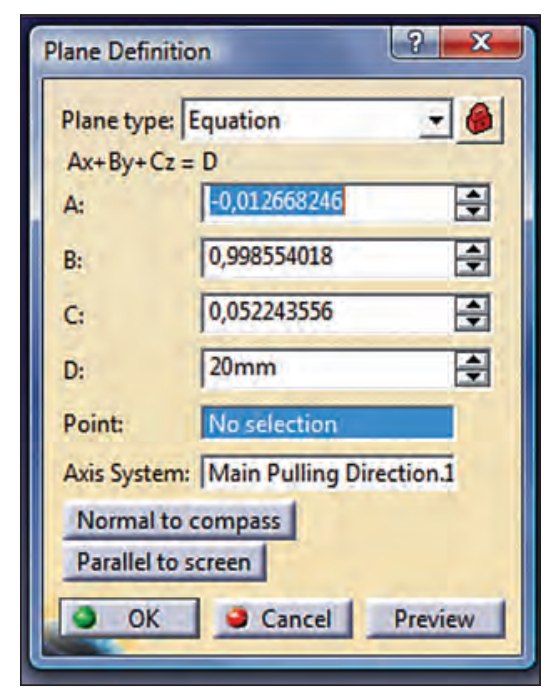

Fig. 9. Dialog window of „Plane Definition” tool

In order to check the distribution of forming angle for each surface part the visualisation option „Shading with material” should be selected and "Draft Analysis" tool should be run and the options as in Fig. 10 should be followed. From the area called "Direction" the icon of a compass should be dragged onto the previously generated line of formation direction in such as way that $-0 \mathrm{Z}$ axis was parallel to the line. Then the area for analysis must be marked with the mouse. In the "mode" window the enlarged colour scale should be selected and each colour should be attributed to the individual angle. In this way a set of colours showing the distribution of forming angle is presented.

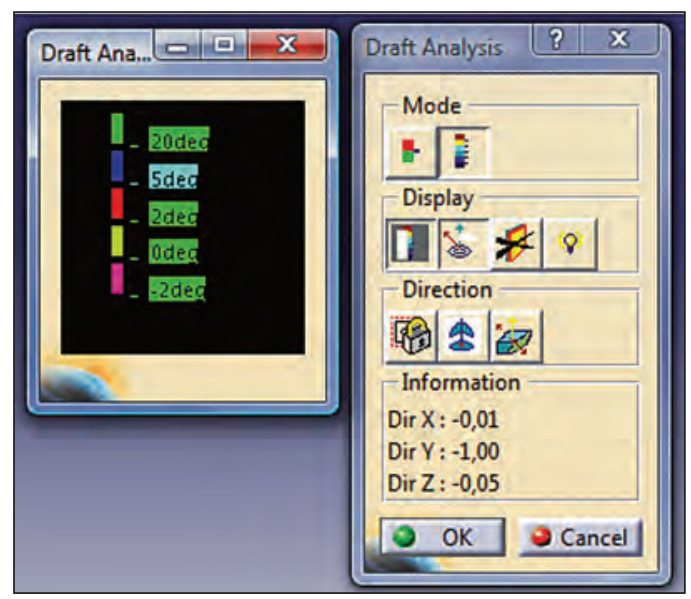

Fig. 10. Dialog window of „Draft Analysis” tool

In case of the analysed surface, minimum angle of $5^{\circ}$ was assumed and marked with blue colour. Each part of the surface characterised by the angle between $2^{\circ}$ and $5^{\circ}$ is described with red colour. The angles between $2^{\circ}$ and $180^{\circ}$ are visualised with black colour. 


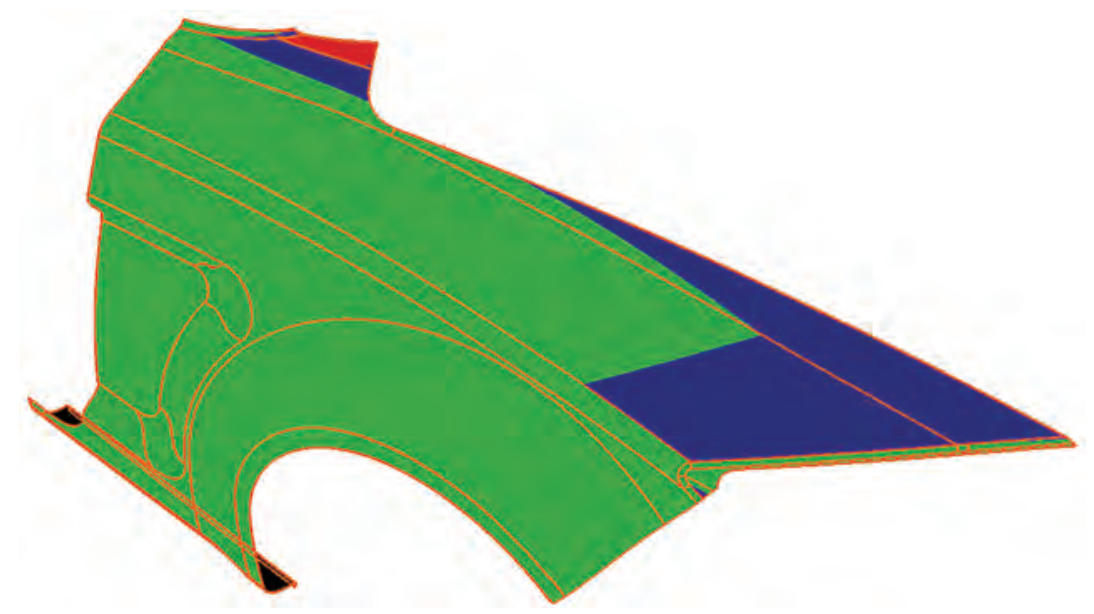

Fig. 11. The analysis of formation angle in a front wing

The edge of cutting divides the sheet metal element into two area: the former cooperates with the die and the latter with the matrix. the forming angle of both the matrix and the die should be larger than the assumed minimum angle. Otherwise, the part will be unworkable or it will have to be formed in a number of operations, what increases the production costs.

In the discussed example the upper part of the wing (Fig. 11, marked with red) in the area of window joint and A column, is characterised by the angle within the range $2-5^{\circ}$. Similar situation is observed in the are of connecting the wing with the floor sheet. The value of angle that is lower than the assumed value may cause the obstruction of the pressed element in the tool. Therefore, because the critical sphere covers a small area, the risk of interference is low.

In Catia, there is no tool that allows for analysing the depth of pressing. Initial verification of manufacturability in this respect is based on technologist's experience and the final one requires a prototype of the tool and the pressed element. Because the discussed wing is characterised by relatively simple geometry, one can assume that it does not include the areas threatened by ruffling or breaking the metal sheet.

\section{CONCLUSION}

Individual stages of construction are connected to one another in such a way to ensure complete associativeness of the model. Most geometries were based on the surface copied from the "Strak..." or on the resultant operations based on them. In case of changes in car design, it is enough to change the old surface into the new one and update the model. If a need arises to change e.g. the door plating, it is enough to make changes in one sketch and the whole related geometry, i.e. the places of holes, shape of stamping, etc., change automatically during the update. Such a construction of models saves time in a situation of inevitable changes.

The present article shows a methodology of developing $\mathrm{CAD}$ models in order to ensure the highest level of associativeness and manufacturability. The methods are used by leading car concerns. In the development process, changes are inevitable for constructors. Therefore, attempts are made to save time on changes in CAD models' geometry. In case of logical, associative construction, a change in one parameter responsible for a function of the constructed part is enough to make changes in all the part after the update.

\section{REFERENCES}

1. Anselm D.: Die PKW-Karosserie. Vogel Business Media; Auflage: 2, Aufl., 2001.

2. Rusiński E.: Zasady projektowania konstrukcji nośnych pojazdów samochodowych. Oficyna wydawnicza Politechniki Wrocławskiej, Wrocław 2002.

3. Braess H.-H., Seiffert U.: Vieweg Handbuch Kraftfahrzeugtechnik. GWV Fachverlage, 2003.

4. http://www-home.htwg-konstanz.de, styczeń 2011.

5. http://www.rucker.pl/index.php?id=4\&id2=4_1, styczeń 2011.

6. Pippert H.: Karosserietechnik. Vogel Verlag Und Druck, 1998.

7. Zieliński A.: Konstrukcja nadwozi samochodów osobowych i pochodnych. WKiE, Warszawa 2004. 